\title{
Antiproliferative Factor Signaling and Interstitial Cystitis/Painful Bladder Syndrome
}

\author{
Jayoung $\mathrm{Kim}^{1-3}$, Michael R. Freeman ${ }^{1-3}$ \\ ${ }^{1}$ Division of Cancer Biology and Therapeutics, Departments of Surgery and Biomedical Sciences, Samuel Oschin Comprehensive Cancer Institute, \\ Cedars-Sinai Medical Center, Los Angeles, CA; \\ ${ }^{2}$ The Urological Diseases Research Center, Children's Hospital Boston, Boston, MA; \\ ${ }^{3}$ Departments of Surgery and Biological Chemistry and Molecular Pharmacology, Harvard Medical School, Boston, MA, USA
}

A unique glycopeptide, antiproliferative factor (APF), has been suggested as a urinary biomarker and potential mediator of longterm bladder disorder Interstitial Cystitis/Painful Bladder Syndrome. There is no known cause for this disease. Several mechanistic approaches have been employed to address the underlying mechanism whereby APF regulates cellular responses in the bladder epithelium. A summary of recent literature is provided, and is focused on signal transduction pathways and networks that are responsive to $\mathrm{APF}$.

Keywords: Human antiproliferative factor APF; Interstitial Cystitis; Signal transduction

\section{INTRODUCTION}

\section{Interstitial Cystitis/Painful Bladder Syndrome (IC/PBS)}

A chronic bladder disorder, IC/PBS, affects over 1 out of 77 Americans ( 3 to 8 million women and 1 to 4 million men). Clinopathological processes underlying this disease have not yet been elucidated, clinical biological markers of the condition are not available, and the type and severity of symptoms can vary. Consequently, an unambiguous clinical definition of the condition is not yet possible [1-8]. It is not understood whether IC/PBS is a systemic disease or whether it originates from the bladder and/or other pelvic organs $[5,9]$. Thus, IC/PBS is a controversial subject and there is still much to be leaned about this disease [10].

\section{Diagnosis}

IC/PBS patients are generally diagnosed according to certain clinical criteria, such as National Institute of Diabetes and Digestive and Kidney Diseases guidelines, which contain inclusion clinical diagnostic criteria using symptoms combined with cystoscopic observations, in the absence of other bladder dis- eases (e.g., overactive bladder, bacterial cystitis, neurogenic bladder, stress incontinence, urological cancer [bladder or prostate cancers], or benign prostatic hypertrophy, and chronic pelvic prostatic symptoms) [1,2,5,6,10-14]. Hydrodistension has been used as part of a diagnostic algorithm. Accumulating scientific data on diagnostics show that cystoscopy and hydrodistension may not be sufficiently sensitive or specific $[13,14]$. Other diagnostic tests can involve results from urine analysis, urine culture, biopsy of the bladder wall and urethra, specific questionnaires to assess the condition (e.g., pain score), the potassium sensitivity test, and/or the anesthetic bladder challenge $[1,15,16]$. However, there is no single diagnostic gold standard. In the absence of agreed-upon diagnostic tests, IC/PBS criteria have not been consistently applied for diagnosis in clinical medicine [4].

Recently, new guidelines by the American Urological Association (AUA) IC/PBS guidelines committee suggest a management strategy for the IC/PBS patient [17]. This recommendation was based on an extensive literature review of 86 articles containing information on application of inclusion and exclusion criteria toward IC/PBS patients. The AUA guidelines suggest conservative, noninvasive approaches involving diet change,
Corresponding author: Jayoung Kim

Division of Cancer Biology and Therapeutics, Departments of Surgery and Biomedical Sciences, Samuel Oschin Comprehensive Cancer Institute, Cedars-Sinai Medical Center, 8700 Beverly Blvd., Los Angeles, CA 90048, USA Tel: +1-310-423-7168 / E-mail: Jayoung.Kim@cshs.org

Submitted: November 30, 2011 / Accepted after revision: December 20, 2011
This is an Open Access article distributed under the terms of the Creative Commons Attribution Non-Commercial License (http://creativecommons.org/licenses/by-nc/3.0/) which permits unrestricted non-commercial use, distribution, and reproduction in any medium, provided the original work is properly cited. 
physical therapy for symptom relief and stress management $[8,16,17]$. Overall, this recommendation outlines five levels of treatment, including pain management.

\section{Treatment}

Treatment of IC/PBS remains challenging. Although medical treatments and procedures, such as bladder instillation, hydrodistension, and oral pharmaceutical drugs are prescribed for those afflicted with the disease $[1,13,17,18]$, these therapies are effective in only a small percentage of patients and most cause undesirable side effects [19]. Oral medications include pentosan polysulfate (Elmiron), antihistamines, tricyclic antidepressants, and immune modulators. Intravesical medications include dimethyl sulfoxide (DMSO), pentosan polysulfate, and heparin. Elmiron is the only oral therapy, and DMSO-based therapy is the only intravesical therapy, with Food and Drug Administration-approval for the treatment of IC/PBS [18]. The most commonly prescribed IC/PBS medication is Elmiron; however, symptom relief by this drug is only for 30 to $60 \%$ of patients. Side effects such as hair loss and gastrointestinal disturbance are commonly observed after treatment is initiated [18].

\section{POTENTIAL BIOMARKERS OF IC/PBS}

Since current IC/PBS diagnosis is generally based on symptoms and exclusion of other bladder disorders, identification of objective biomarkers, phenotyping and characterization of pathology would represent a major advance [11,20-22]. Although there are substantial limitations and roadblocks to implementing biomarker discovery, there is a tremendous need for specific and sensitive biomarkers in this field $[9,15,23]$. Biomarkers can be used for diagnosis and/or for tracking the treatment response of patients, which can reduce clinical burden. Biomarkers in urine or blood are favorable, since their application requires less invasive methods [23].

Searches for an objective urinary IC/PBS biomarker have led to the identification of several candidates such as substance $P$, uroplakin III- $\delta 4$ mRNA, interleukin-6, cyclic guanosine monophosphate, uromodulin, kininogens, inter- $\alpha$-trypsin inhibitor heavy chain $\mathrm{H} 4$, nitric oxide, nerve growth factor, heparin-binding epidermal growth factor-like growth factor (HB-EGF) and antiproliferative factor (APF) [15,24-33]. There are still a lot of discrepancies on strong correlation to severity (e.g., pain and symptom score), clinical course and responsiveness to treatments (e.g., steroid or oral prednisolone) in IC/PBS patients, compared to their age-, race- and gender-matched controls.

\section{HB-EGF, EGF and APF}

Three urinary biomarkers identified from IC/PBS patient material were found by Keay et al. [25,34]: epidermal growth factor (EGF) and APF concentrations in urine were positively correlated with presence of disease, while HB-EGF exhibited an inverse correlation in urine of IC/PBS patients, compared to controls (urine from patients without IC/PBS).

EGF and HB-EGF are potent urothelial and smooth muscle cell mitogens, and enhance proliferation [35,36]. EGF is a product of many epithelial cells and was the first activating ligand for the epidermal growth factor receptor (EGFR) identified [37]. HB-EGF is initially expressed as a transmembrane precursor (proHB-EGF), with the soluble form generated by the regulated metalloproteinase-dependent ectodomain shedding. Secreted soluble HB-EGF activates mitogenic and cell survival functions, while proHB-EGF acts as a juxtacrine factor and also mediates translocation of diphtheria toxin from the cell surface to the cytosol. In addition to activation of the EGFR, HB-EGF is also a direct activating ligand for the related tyrosine kinase, ErbB4/ HER4 [36,38]. EGF and HB-EGF are present under normal conditions in human urine, and the levels are altered in patients with IC/PBS [25,34]. Concentrations of HB-EGF and EGF change in an inverse manner (EGF levels are higher and HBEGF levels are lower) in IC/PBS patients [34].

APF is a small, 8 amino acid sialoglycosylated peptide identified in IC/PBS patients. Bioactivities attributed to APF include: suppression of cell growth; increases of transcellular permeability; lowering of the expression of proteins that form intercellular junctional complexes; and reduction of HB-EGF production from urothelial cells [39]. APF is originally purified from the urine specimens of IC/PBS patients using high performance liquid chromatography $[24,40,41]$, and recently a bioactive, synthetic form of the glycopeptide was reported [42]. APF activity is detected in the urine of approximately $95 \%$ of IC/PBS patients (as compared to approximately $9 \%$ of controls).

\section{APF AND IC/PBS}

The accumulation in urine of the bioactive factor APF, which is capable of altering the physiology and behavior of urothelial cells, is consistent with clinical observations of epithelial thinning and denudation observed in IC/PBS bladder tissue. In $v i$ tro, APF is synthesized and secreted from bladder epithelial cells 
derived from patients diagnosed as IC/PBS, but not from asymptomatic controls [41]. APF is 100\% homologous to the 6th transmembrane domain of membrane receptor frizzled-8, in the Wnt signaling network. APF is acidic, heat-stable and glycosylation is required for biological activity. The structure of APF (Neu5Aca2-3Galß1-3GalNAca-O-TVPAAVVVA) was deduced by a series of processing steps, involving ion trap mass spectrometry, enzymatic digestion, lectin affinity chromatography, and microcapillary reversed-phase liquid chromatography/ mass spectrometry (MS) [24].

Both chemically synthesized and native APF (purified from urine or explants from biopsies from patients with IC/PBS) had identical biological activity in normal bladder epithelial cells and several types of cancer cells including T24 bladder cancer cells $[24,42,43]$. These findings suggest that APF is not only a urinary biomarker but also a potential mediator of the pathogenic changes seen in IC/PBS.

\section{APF SIGNALING}

In order to determine the potential etiologies of IC/PBS, and to identify molecular and cellular differences between IC/PBS patients and controls, understanding the molecular mechanisms of the various effects induced by APF has been attempted. Denudation or thinning of the epithelium is commonly observed in bladder biopsies from patients with IC/PBS, suggesting cell proliferation is hindered in IC/PBS cells [40,44]. Although the exact etiology is unknown, the impermeability of the bladder barrier is increased, resulting in a leaky bladder epithelium and potassium leakage, potentially a source of origin for IC/PBS symptoms (such as frequency, urgency, pelvic pain or incontinence) [45]. Additional bladder dysfunction includes increased nerve fiber density and inflammatory infiltrates (e.g., mast cell and/or lymphocytic), which are correlated to the increased pain and cytokine production in IC/PBS bladder [46-48]. To understand the underlying mechanisms, several laboratories have focused on abnormal cell signaling induced in presence of APF in bladder epithelial cells. As we will discuss below, these led to the following observations that 1) cytoskeleton-associated protein 4 (CKAP4 or CLIMP63) plays a role as an APF receptor [42,49, 50]; 2) the palmitoylation status of CKAP4 is important for APF signal transduction [39,49]; 3) mitogen-activated protein kinase (MAPK) signal pathways were altered by APF [39,51]; 4) phosphorylation of Akt and its target, glycogen synthase kinase (GSK), is induced by APF treatment $[42,52]$; 5) the p52-p21 signal pathway is enhanced in the presence of APF, leading to inhibition of cell proliferation [52]; and 6) a quantitative proteomics analysis and bioinformatics identified $\beta$-catenin as a prominent hub molecule in APF-induced signaling [53].

\section{APF Receptor, CKAP4/CLIMP63}

Zhang et al. [54] found that APF binds to a high affinity cell surface receptor, CKAP4/CLIMP63, which mediates APF signaling in bladder epithelial cells, using the palmitoyl-cysteine identification capture and analysis method. In general, palmitoylation (S-acylation) of transmembrane proteins regulates subcellular trafficking and/or protein degradation [55]. S-acylation of CKAP4/p63 is required for its proper localization into the plasma membrane by Asp-His-His-Cys protein (DHHC), a specific palmitoyl acyltransferase and a putative tumor suppressor [54]. APF binds to membrane resident palmitoylated CKAP4, resulting in an inhibition of cell proliferation and alteration of the expression of genes relevant to cell-to-cell permeability (e.g., E-cadherin, vimentin, and tight junction protein, ZO-1) $[54,56]$. Interestingly, DHHC2-mediated CKAP4/p63 palmitoylation mediates CKAP4/p63 trafficking from the ER to the surface membrane and/or to nucleus, suggesting that DHHC2 activity is critical to the APF-mediated signaling requiring CKAP4/p63 $[49,55]$. The potential correlation of expression of CKAP4/p63, DHHC2 and sensitivity to APF remains to be tested.

\section{MAPK Signal Pathways}

Various biological responses in response to APF accompany the perturbed signal transduction pathways [39]. The possible role of the MAPK pathways (including Erk/MAPK, p38MAPK, and c-Jun N-terminal kinases/stress-activated protein kinase [JNK/ SAPK] signaling) in IC/PBS are not well understood, in spite of importance of MAPK signaling in epithelial, endothelial, and fibroblast cell proliferation $[57,58]$. Although there are important differences between tissues and cell types, Erk, p38 and JNK/SAPK MAPK pathways often exert opposing functions and undergo extensive cross-talk in regulating proliferation and cell death.

APF treatment has been reported to result in the increased p38MAPK phosphorylation and suppressed cell growth, which were both reversed by a p38MAPK-selective inhibitor [51]. Very recently, Li et al. [59] reported that a transcription factor in the JNK/SAPK pathway, c-Jun, involves in growth suppression by APF. APF also induced a significant decrease in c-Jun expression in concert with growth inhibition. Enforced c-Jun expres- 
sion reversed APF inhibitory effects on cell growth. These results show that JNK/SAPK expression may also be important for control of uroepithelial cell proliferation, with JNK1 levels decreased in both IC/PBS cells (compared to controls) and APFtreated normal bladder epithelial cells (compared to control peptide-treated) $[45,59]$.

\section{Akt Pathway}

Activation of the a serine-threonine kinase, Akt/protein kinase $\mathrm{B}$, is generally important to cell proliferation, migration and survival [60-62]. There are three isoforms, Akt1, Akt2, and Akt3, which show differential functions in cancer cells $[62,63]$. Phosphorylation of Akt/PKB occurs at Ser473 and Thr308 [61-63]. Recent studies have shown that the rapamycin-insensitive rictor-mTOR complex (mTORC2) and DNA-dependent protein kinase both directly phosphorylates Akt at Ser473 [64,65]. However, it has not been shown whether Akt or Akt-related molecules (e.g., PI3-Kinase and GSK) are related to IC/PBS, except a very recent paper showing that $\mathrm{APF}$ treatment downregulates Akt signaling in bladder epithelial cells [42]. Phosphorylation of Akt (at Ser473 and Thr308), GSK3 $\beta$ (at Tyr216) and $\beta$-catenin (at Ser45/Thr41) were decreased by APF treatment, suggesting that APF downregulates Akt and its downstream signaling network, which is consistent with the growth arrest observed in IC/PBS cells. It has not been tested whether this downregulation of Akt signaling in response to APF is dependent on PI3kinase or the PTEN pathway, which is an important upstream inhibitor of Akt signaling [66,67].

\section{p53-p21 Signaling}

Activation of the $\mathrm{p} 53$ pathway is stimulated by stress signals (such as DNA damage and oxidative stress) and activated oncogenes [68-70]. As a transcription factor, p53 controls the expression of p53-regulated genes [71,72], resulting in cell cycle arrest, cellular senescence, apoptotic cell death, or repair of damaged DNA [73,74]. Loss of p53 function is one of the common genetic alterations observed in human cancer cells $[73,75,76]$.

The signaling mechanisms by which APF induces its antiproliferative activity are of considerable interest. Treatment of normal human urothelial cells, and T24 human bladder carcinoma cells with APF increased p53 levels [52]. Changed p53 level altered the APF effect on cell growth, indicating that $\mathrm{p} 53$ is involved in the mechanism of APF-induced growth suppression observed in the context of IC/PBS. p53 down-regulation enhanced the suppressive effect of APF on cell growth, while ecto- pic p53 expression induced cell cycle arrest in the absence of APF. One of the p53 targets, p 21 was induced by APF treatment in presence of p53, implying that p53-p21 signaling is an important mediator of APF-induced effects on bladder epithelial cells [52]. Some p53-interacting proteins, including herpesvirus-associated ubiquitin-specific protease, homeodomain-interacting protein kinase 2, ataxia telangiectasia mutated (ATM), ATM and RAD3-related, and heterogeneous nuclear ribonucleoprotein $\mathrm{K}$, are known to stabilize p53 and increase expression level [68,77-80]. Phosphorylation of $\mathrm{p} 53$ at specific sites protects p53 from degradation by murine double minute $[81,82]$. However, the specific mechanism by which APF regulates p53 and p21 levels in the IC/PBS context is not clearly understood. Additional studies on the 53 modification status in response to APF remain to be undertaken.

\section{$\beta$-catenin in IC/PBS}

In order to identify IC/PBS-specific pathogenetic mechanisms and biomarkers, efforts have been focused on genomic, proteomic and metabolomic patterns to distinguish IC/PBS from other bladder diseases. These studies were often combined with a systems-biology approach with microarray, MS and proton nuclear magnetic resonance (1H-NMR)-based spectral patterns $[45,83]$.

Over about 100 significantly changed proteins following APF treatment were identified by stable isotope labeling by amino acids in cell culture (SILAC) quantitative proteomics [53]. $\beta$-catenin was found to be the most prominent and functionally relevant protein in the APF signaling network by various functional validation assays. Bioinformatics analysis with data integration of the in vitro SILAC data with in vivo RNA expression data obtained from IC/PBS patients identified cyclooxygenase- 2 $(\mathrm{COX}-2)$ as an effector of $\beta$-catenin in IC/PBS. In bladder epithelial cells from IC/PBS patients, the expression level of $\beta$-catenin was correlated to level of COX-2 [53]. These findings suggest that inflammation associated with IC/PBS may be caused, at least in part, by APF. These findings imply that targeting the $\beta$-catenin-COX-2 signaling pathway in addition to APF may be a rational approach toward treating IC/PBS.

\section{THERAPEUTIC IMPLICATION OF APF RESEARCH}

\section{HB-EGF as an APF Antagonist}

One interesting feature of the existing urinary biomarkers of 
IC/PBS is the functional relationship between APF and HBEGF. First, levels of these two biomarkers are inversely correlated in IC/PBS patient urine [25,41]. Second, this inversed pattern has been observed after cystoscopic hydrodistention, a common clinical procedure to relieve IC/PBS-related symptoms. Application of hydrodistention significantly increased HB-EGF levels and decreased APF activity in urine [84]. Third, APF was shown to decrease HB-EGF production by normal human bladder epithelial cells in vitro, and concentrations of recombinant human HB-EGF, similar to those found in normal human urine specimens, were shown to abrogate the effects of APF on human bladder epithelial cells [40]. Lastly, removal of APF from the culture medium induced HB-EGF production and recovery of cell proliferation [51]. Together, these results suggest that HB-EGF and APF are functionally antagonistic biopeptides.

Further investigation on the underlying mechanisms of the bioactivity relationship between HB-EGF and APF has revealed the involvement of signal transduction pathways perturbed by them. HB-EGF and APF are functionally antagonistic due to signals through parallel MAPK signaling pathways: activated Erk/MAPK by HB-EGF is inhibited by APF, and APF cannot stimulate p38MAPK in the presence of soluble HB-EGF (or when cells overexpressed constitutively secreted HB-EGF) [51].

Although the mechanism of the hydrodistention effect has not been clearly known hydrodistension therapy has been introduced to relief IC/PBS symptoms [14]. IC/PBS symptom scores were decreased $56 \%$ in a cohort of patients after hydrodistension [14]. One suggested hypothesis is that bladder distention may increase the capacity to reduce pain signals transmitted by the nervous system. Hydrodistention also results in an increase of HB-EGF levels in urine and a reduction of urine APF activity [84]. The functional correlation of APF and HBEGF through crosstalk between signal pathways provides a mechanistic basis for the reported therapeutic effects of hydrodistension to relief IC/PBS symptoms, one consequence of which is increased intraluminal concentrations of HB-EGF, an APF antagonist.

\section{Inactive APF Derivatives}

Chemically synthesized asialylated APF (as-APF) exhibited similar antiproliferative effects on normal bladder epithelial cells. Removal of the sialic acid unit from as-APF did not affect its biological activity. Over 40 synthetic APF analogues were recently screened to identify inactive APF derivatives for their ability to block antiproliferative activity of as-APF in normal bladder cells [43]. Two inactive as-APF derivatives, D-proline as-APF, GalB1-3GalNAca-O-TV-(d-pipecolic acid)-AAVVVA, and D-pipecolic acid as-APF, Gal $\beta 1$-3GalNAca-O-TV-(dproline)-AAVVVA were found to block as-APF antiproliferative activity in normal bladder epithelial cells. Furthermore, these as-APF derivatives were able to recover the altered tight junction protein expression, paracellular permeability, and/or proliferation of IC/PBS cells [43].

\section{CONCLUDING REMARKS}

The purpose of this review was to revisit the published literature showing evidence for a biological role of APF in IC/PBS, with a focus on APF-induced gene expression and signaling network alterations. We also discuss some potential therapeutic strategies for this bladder disorder based on the functions of APF antagonists.

Clinical diagnosis of IC/PBS largely relies on the exclusion of other bladder diseases. Pathologic and biologic tools for diagnosis are sorely needed. However, it is encouraging that IC/PBS biomarkers have been identified in patient urine, suggesting that non-invasive methods using quantitative and accurate diagnostic criteria may be possible. Our understanding of the origins and molecular mechanisms of this debilitating disease are limited and contradictory. Much work needs to be undertaken to refine the currently existing candidate biomarkers. Ongoing efforts in the IC/PBS field include mechanistic studies to enhance our understanding of etiology and disease progression, and to develop IC/PBS drugs using the inactive analogues of APF. Accumulating evidence also suggests the potential for APF signaling network-targeting therapy and deserves greater experimental attention.

\section{CONFLICT OF INTEREST}

No potential conflict of interest relevant to this article was reported.

\section{ACKNOWLEDGEMENTS}

This manuscript is supported by grants from NIH grants R01 DK087806, R01 CA143777 and P50 DK65298 (to M.R.F.); the Fishbein Family IC Research Foundation/Interstitial Cystitis Association (ICA), Pilot Research Program/ICA, New York 
Academy of Medicine, and Children's Hospital Boston Faculty Development (to J.K.). J.K. is an American Urological Association Foundation Research Scholar and a Harvard Medical School Eleanor and Miles Shore Scholar.

The funders had no role in study design, data collection and analysis, decision to publish, or preparation of the manuscript.

\section{REFERENCES}

1. Hanno P, Levin RM, Monson FC, Teuscher C, Zhou ZZ, Ruggieri M, et al. Diagnosis of interstitial cystitis. J Urol 1990;143:278-81.

2. Hanno P, Keay S, Moldwin R, Van Ophoven A. International Consultation on IC - Rome, September 2004/Forging an International Consensus: progress in painful bladder syndrome/interstitial cystitis. Report and abstracts. Int Urogynecol J Pelvic Floor Dysfunct 2005;16 Suppl 1:S2-34.

3. Parsons CL, Lilly JD, Stein P. Epithelial dysfunction in nonbacterial cystitis (interstitial cystitis). J Urol 1991;145:732-5.

4. Sant GR, Hanno PM. Interstitial cystitis: current issues and controversies in diagnosis. Urology 2001;57(6 Suppl 1):82-8.

5. Nordling J, Anjum FH, Bade JJ, Bouchelouche K, Bouchelouche P, Cervigni M, et al. Primary evaluation of patients suspected of having interstitial cystitis (IC). Eur Urol 2004;45:662-9.

6. Bogart LM, Berry SH, Clemens JQ. Symptoms of interstitial cystitis, painful bladder syndrome and similar diseases in women: a systematic review. J Urol 2007;177:450-6.

7. Tomaszewski JE, Landis JR, Russack V, Williams TM, Wang LP, Hardy C, et al. Biopsy features are associated with primary symptoms in interstitial cystitis: results from the interstitial cystitis database study. Urology 2001;57(6 Suppl 1):67-81.

8. Phatak S, Foster HE Jr. The management of interstitial cystitis: an update. Nat Clin Pract Urol 2006;3:45-53.

9. Warren JW, Keay SK. Interstitial cystitis. Curr Opin Urol 2002;12: 69-74.

10. Berry SH, Elliott MN, Suttorp M, Bogart LM, Stoto MA, Eggers P, et al. Prevalence of symptoms of bladder pain syndrome/interstitial cystitis among adult females in the United States. J Urol 2011;186: 540-4.

11. Moutzouris DA, Falagas ME. Interstitial cystitis: an unsolved enigma. Clin J Am Soc Nephrol 2009;4:1844-57.

12. Clemens JQ, Stoto MA, Elliott M, Suttorp M, Bogart L, Berry SH. Prevalence of interstitial cystitis/painful bladder syndrome in the United States [abstract]. Neurourol Urodyn 2009:28;907. Meeting abstract no. 261.

13. Johansson SL, Fall M. Clinical features and spectrum of light mi- croscopic changes in interstitial cystitis. J Urol 1990;143:1118-24.

14. Ottem DP, Teichman JM. What is the value of cystoscopy with hydrodistension for interstitial cystitis? Urology 2005;66:494-9.

15. Parsons CL, Greenberger M, Gabal L, Bidair M, Barme G. The role of urinary potassium in the pathogenesis and diagnosis of interstitial cystitis. J Urol 1998;159:1862-6.

16. Persu C, Cauni V, Gutue S, Blaj I, Jinga V, Geavlete P. From interstitial cystitis to chronic pelvic pain. J Med Life 2010;3:167-74.

17. Hanno PM, Burks DA, Clemens JQ, Dmochowski RR, Erickson D, Fitzgerald MP, et al. AUA guideline for the diagnosis and treatment of interstitial cystitis/bladder pain syndrome. J Urol 2011;185:216270.

18. Hanno PM. Analysis of long-term Elmiron therapy for interstitial cystitis. Urology 1997;49(5A Suppl):93-9.

19. Bouchelouche K, Nordling J. Recent developments in the management of interstitial cystitis. Curr Opin Urol 2003;13:309-13.

20. Erickson DR, Xie SX, Bhavanandan VP, Wheeler MA, Hurst RE, Demers LM, et al. A comparison of multiple urine markers for interstitial cystitis. J Urol 2002;167:2461-9.

21. Keay S, Zhang CO, Hise MK, Hebel JR, Jacobs SC, Gordon D, et al. A diagnostic in vitro urine assay for interstitial cystitis. Urology 1998;52:974-8.

22. Moldwin RM, Evans RJ, Stanford EJ, Rosenberg MT. Rational approaches to the treatment of patients with interstitial cystitis. Urology 2007;69(4 Suppl):73-81.

23. Slobodov G, Feloney M, Gran C, Kyker KD, Hurst RE, Culkin DJ. Abnormal expression of molecular markers for bladder impermeability and differentiation in the urothelium of patients with interstitial cystitis. J Urol 2004;171:1554-8.

24. Keay SK, Szekely Z, Conrads TP, Veenstra TD, Barchi JJ Jr, Zhang $\mathrm{CO}$, et al. An antiproliferative factor from interstitial cystitis patients is a frizzled 8 protein-related sialoglycopeptide. Proc Natl Acad Sci U S A 2004;101:11803-8.

25. Keay S, Zhang CO, Marvel R, Chai T. Antiproliferative factor, heparin-binding epidermal growth factor-like growth factor, and epidermal growth factor: sensitive and specific urine markers for interstitial cystitis. Urology 2001;57(6 Suppl 1):104.

26. Kim JC, Park EY, Seo SI, Park YH, Hwang TK. Nerve growth factor and prostaglandins in the urine of female patients with overactive bladder. J Urol 2006;175:1773-6.

27. Liu HT, Tyagi P, Chancellor MB, Kuo HC. Urinary nerve growth factor but not prostaglandin E2 increases in patients with interstitial cystitis/bladder pain syndrome and detrusor overactivity. BJU Int 2010;106:1681-5.

28. Nazif O, Teichman JM, Gebhart GF. Neural upregulation in inter- 
stitial cystitis. Urology 2007;69(4 Suppl):24-33.

29. Chai TC, Keay S. New theories in interstitial cystitis. Nat Clin Pract Urol 2004;1:85-9.

30. Kushner L, Chiu PY, Brettschneider N, Lipstein A, Eisenberg E, Rofeim $\mathrm{O}$, et al. Urinary substance $\mathrm{P}$ concentration correlates with urinary frequency and urgency in interstitial cystitis patients treated with intravesical dimethyl sulfoxide and not intravesical anesthetic cocktail. Urology 2001;57(6 Suppl 1):129.

31. Sanchez Freire V, Burkhard FC, Kessler TM, Kuhn A, Draeger A, Monastyrskaya K. MicroRNAs may mediate the down-regulation of neurokinin-1 receptor in chronic bladder pain syndrome. Am J Pathol 2010;176:288-303.

32. Birder LA, Wolf-Johnston A, Buffington CA, Roppolo JR, de Groat WC, Kanai AJ. Altered inducible nitric oxide synthase expression and nitric oxide production in the bladder of cats with feline interstitial cystitis. J Urol 2005;173:625-9.

33. Jacobs BL, Smaldone MC, Tyagi V, Philips BJ, Jackman SV, Leng $\mathrm{WW}$, et al. Increased nerve growth factor in neurogenic overactive bladder and interstitial cystitis patients. Can J Urol 2010;17:4989-94.

34. Keay S, Zhang CO, Kagen DI, Hise MK, Jacobs SC, Hebel JR, et al. Concentrations of specific epithelial growth factors in the urine of interstitial cystitis patients and controls. J Urol 1997;158:1983-8.

35. Ongusaha PP, Kwak JC, Zwible AJ, Macip S, Higashiyama S, Taniguchi N, et al. HB-EGF is a potent inducer of tumor growth and angiogenesis. Cancer Res 2004;64:5283-90.

36. Freeman MR, Yoo JJ, Raab G, Soker S, Adam RM, Schneck FX, et al. Heparin-binding EGF-like growth factor is an autocrine growth factor for human urothelial cells and is synthesized by epithelial and smooth muscle cells in the human bladder. J Clin Invest 1997; 99:1028-36.

37. Schneider MR, Wolf E. The epidermal growth factor receptor ligands at a glance. J Cell Physiol 2009;218:460-6.

38. Kim J, Adam RM, Freeman MR. Trafficking of nuclear heparinbinding epidermal growth factor-like growth factor into an epidermal growth factor receptor-dependent autocrine loop in response to oxidative stress. Cancer Res 2005;65:8242-9.

39. Keay S. Cell signaling in interstitial cystitis/painful bladder syndrome. Cell Signal 2008;20:2174-9.

40. Keay S, Zhang CO, Shoenfelt JL, Chai TC. Decreased in vitro proliferation of bladder epithelial cells from patients with interstitial cystitis. Urology 2003;61:1278-84.

41. Keay S, Kleinberg M, Zhang CO, Hise MK, Warren JW. Bladder epithelial cells from patients with interstitial cystitis produce an inhibitor of heparin-binding epidermal growth factor-like growth factor production. J Urol 2000;164:2112-8.
42. Shahjee HM, Koch KR, Guo L, Zhang CO, Keay SK. Antiproliferative factor decreases Akt phosphorylation and alters gene expression via CKAP4 in T24 bladder carcinoma cells. J Exp Clin Cancer Res 2010;29:160.

43. Keay S, Kaczmarek P, Zhang CO, Koch K, Szekely Z, Barchi JJ Jr, et al. Normalization of proliferation and tight junction formation in bladder epithelial cells from patients with interstitial cystitis/painful bladder syndrome by d-proline and d-pipecolic acid derivatives of antiproliferative factor. Chem Biol Drug Des 2011;77:421-30.

44. Keay S, Zhang CO, Trifillis AL, Hise MK, Hebel JR, Jacobs SC, et al. Decreased $3 \mathrm{H}$-thymidine incorporation by human bladder epithelial cells following exposure to urine from interstitial cystitis patients. J Urol 1996;156:2073-8.

45. Keay S, Seillier-Moiseiwitsch F, Zhang CO, Chai TC, Zhang J. Changes in human bladder epithelial cell gene expression associated with interstitial cystitis or antiproliferative factor treatment. Physiol Genomics 2003;14:107-15.

46. Lee T. New insights into the mechanism of the down-regulation of mast cells in the treatment of interstitial cystitis: possible role of siglecs. Int Neurourol J 2011;15:59-60.

47. Rudick CN, Bryce PJ, Guichelaar LA, Berry RE, Klumpp DJ. Mast cell-derived histamine mediates cystitis pain. PLoS One 2008;3: e2096.

48. Shie JH, Kuo HC. Higher levels of cell apoptosis and abnormal Ecadherin expression in the urothelium are associated with inflammation in patients with interstitial cystitis/painful bladder syndrome. BJU Int 2011;108(2 Pt 2):E136-41.

49. Planey SL, Keay SK, Zhang CO, Zacharias DA. Palmitoylation of cytoskeleton associated protein 4 by DHHC2 regulates antiproliferative factor-mediated signaling. Mol Biol Cell 2009;20:1454-63.

50. Conrads TP, Tocci GM, Hood BL, Zhang CO, Guo L, Koch KR, et al. CKAP4/p63 is a receptor for the frizzled-8 protein-related antiproliferative factor from interstitial cystitis patients. J Biol Chem 2006; 281:37836-43.

51. Kim J, Keay SK, Freeman MR. Heparin-binding epidermal growth factor-like growth factor functionally antagonizes interstitial cystitis antiproliferative factor via mitogen-activated protein kinase pathway activation. BJU Int 2009;103:541-6.

52. Kim J, Keay SK, Dimitrakov JD, Freeman MR. p53 mediates interstitial cystitis antiproliferative factor (APF)-induced growth inhibition of human urothelial cells. FEBS Lett 2007;581:3795-9.

53. Yang W, Chung YG, Kim Y, Kim TK, Keay SK, Zhang CO, et al. Quantitative proteomics identifies a beta-catenin network as an element of the signaling response to Frizzled-8 protein-related antiproliferative factor. Mol Cell Proteomics 2011;10:M110.007492. 
54. Zhang J, Planey SL, Ceballos C, Stevens SM Jr, Keay SK, Zacharias DA. Identification of CKAP4/p63 as a major substrate of the palmitoyl acyltransferase DHHC2, a putative tumor suppressor, using a novel proteomics method. Mol Cell Proteomics 2008;7:1378-88.

55. Resh MD. Palmitoylation of ligands, receptors, and intracellular signaling molecules. Sci STKE 2006;2006:re14.

56. Zhang CO, Wang JY, Koch KR, Keay S. Regulation of tight junction proteins and bladder epithelial paracellular permeability by an antiproliferative factor from patients with interstitial cystitis. J Urol 2005;174:2382-7.

57. Kim J, Adam RM, Freeman MR. Activation of the Erk mitogen-activated protein kinase pathway stimulates neuroendocrine differentiation in LNCaP cells independently of cell cycle withdrawal and STAT3 phosphorylation. Cancer Res 2002;62:1549-54.

58. Swiatkowski S, Seifert HH, Steinhoff C, Prior A, Thievessen I, Schliess F, et al. Activities of MAP-kinase pathways in normal uroepithelial cells and urothelial carcinoma cell lines. Exp Cell Res 2003;282:48-57.

59. Li Z, Zhu Y, Yu M, Ji D, Yang Z, Kong C. c-Jun is involved in interstitial cystitis antiproliferative factor (APF)-induced growth inhibition of human bladder cancer T24 cells. Urol Oncol 2011 Aug 25 [Epub]. DOI:10.1016/j.urolonc.2010.11.011.

60. Ching CB, Hansel DE. Expanding therapeutic targets in bladder cancer: the PI3K/Akt/mTOR pathway. Lab Invest 2010;90:1406-14.

61. Hers I, Vincent EE, Tavaré JM. Akt signalling in health and disease. Cell Signal 2011;23:1515-27.

62. Dillon RL, Muller WJ. Distinct biological roles for the akt family in mammary tumor progression. Cancer Res 2010;70:4260-4.

63. Gonzalez E, McGraw TE. The Akt kinases: isoform specificity in metabolism and cancer. Cell Cycle 2009;8:2502-8.

64. Bozulic L, Hemmings BA. PIKKing on PKB: regulation of PKB activity by phosphorylation. Curr Opin Cell Biol 2009;21:256-61.

65. Bozulic L, Hemmings BA. PIKKing on PKB: regulation of PKB activity by phosphorylation. Curr Opin Cell Biol. 2009;21:256-61.

66. Knowles MA, Platt FM, Ross RL, Hurst CD. Phosphatidylinositol 3-kinase (PI3K) pathway activation in bladder cancer. Cancer Metastasis Rev 2009;28:305-16.

67. Adam RM, Roth JA, Cheng HL, Rice DC, Khoury J, Bauer SB, et al. Signaling through PI3K/Akt mediates stretch and PDGF-BBdependent DNA synthesis in bladder smooth muscle cells. J Urol 2003;169:2388-93.

68. Braithwaite AW, Del Sal G, Lu X. Some p53-binding proteins that can function as arbiters of life and death. Cell Death Differ 2006;13: 984-93.
69. Bunz F, Dutriaux A, Lengauer C, Waldman T, Zhou S, Brown JP, et al. Requirement for p53 and p21 to sustain G2 arrest after DNA damage. Science 1998;282:1497-501.

70. Chène P. Inhibiting the p53-MDM2 interaction: an important target for cancer therapy. Nat Rev Cancer 2003;3:102-9.

71. Sun Y. p53 and its downstream proteins as molecular targets of cancer. Mol Carcinog 2006;45:409-15.

72. Toledo F, Wahl GM. Regulating the p53 pathway: in vitro hypotheses, in vivo veritas. Nat Rev Cancer 2006;6:909-23.

73. Harris SL, Levine AJ. The p53 pathway: positive and negative feedback loops. Oncogene 2005;24:2899-908.

74. Haupt Y, Maya R, Kazaz A, Oren M. Mdm2 promotes the rapid degradation of p53. Nature 1997;387:296-9.

75. Cooper MJ, Haluschak JJ, Johnson D, Schwartz S, Morrison LJ, Lippa M, et al. p53 mutations in bladder carcinoma cell lines. Oncol Res 1994;6:569-79.

76. Lane DP. Exploiting the p53 pathway for the diagnosis and therapy of human cancer. Cold Spring Harb Symp Quant Biol 2005;70:48997.

77. Chen L, Gilkes DM, Pan Y, Lane WS, Chen J. ATM and Chk2-dependent phosphorylation of MDMX contribute to p53 activation after DNA damage. EMBO J 2005;24:3411-22.

78. Cummins JM, Vogelstein B. HAUSP is required for p53 destabilization. Cell Cycle 2004;3:689-92.

79. Khanna KK, Keating KE, Kozlov S, Scott S, Gatei M, Hobson K, et al. ATM associates with and phosphorylates p53: mapping the region of interaction. Nat Genet 1998;20:398-400.

80. Moumen A, Masterson P, O’Connor MJ, Jackson SP. hnRNP K: an HDM2 target and transcriptional coactivator of p53 in response to DNA damage. Cell 2005;123:1065-78.

81. Meek DW, Hupp TR. The regulation of MDM2 by multisite phosphorylation-opportunities for molecular-based intervention to target tumours? Semin Cancer Biol 2010;20:19-28.

82. MacLaine NJ, Hupp TR. How phosphorylation controls p53. Cell Cycle 2011;10:916-21.

83. Van QN, Klose JR, Lucas DA, Prieto DA, Luke B, Collins J, et al. The use of urine proteomic and metabonomic patterns for the diagnosis of interstitial cystitis and bacterial cystitis. Dis Markers 2003-2004;19:169-83.

84. Chai TC, Zhang CO, Shoenfelt JL, Johnson HW Jr, Warren JW, Keay S. Bladder stretch alters urinary heparin-binding epidermal growth factor and antiproliferative factor in patients with interstitial cystitis. J Urol 2000;163:1440-4. 